\title{
Pesticide Immunoassay
}

\author{
Mingtao Fan and Jiang He \\ Northwest AEF University \\ China P.R.
}

\section{Introduction}

Pesticides are used globally for enhancing crop yields. However, their excessive use/misuse, especially in the developing countries, results in widespread food and environmental contamination. The presence of pesticide residues in food and environment has posed a serious threat to human health and caused a great concern. In order to keep human from being affected, analytical and monitoring system of pesticide residues in food and environment must be developed. Conventional methods employed to detect/analyze the pesticide residue are chromatographic techniques such as gas chromatography (GC), high performance liquid chromatography (HPLC), which are time consuming and require sophisticated equipment only available in well-equipped laboratories. In addition, the conventional methods usually require a lot of complex pre-treatment of samples. Therefore, convenient and rapid pesticide detection system is urgently needed. Immunoassay (IA) technology is such an analysis system with simple, rapid and cost-effective characteristics and widely used in pesticides detection. Thus, the topic of "pesticide immunoassay" will be introduced in this chapter.

An "immunoassay" is a quantitative or qualitative method of analysis for a substance which relies on an antibody $(\mathrm{Ab})$, or mixture of antibodies, as the analytical reagent. Antibodies are a class of proteins with the unique ability to bind with high specificity to one or a very limited group of molecules. A molecule that binds to an antibody is called an antigen (Ag). In addition to binding specificity, another important feature of immunoassays is its ability to produce a measurable signal in response to a specific binding. Most immunoassays today depend on the use of an analytical reagent that is associated with a detectable label, such as radioactive elements, enzymes and so on.

Immunoassay has a rather long history and has become a widely accepted technique, particularly in the clinical area. Beginning in the middle 1950's, Berson and Yalow were investigating the disease, diabetes. To test the hypothesis that diabetic individuals eliminated insulin too rapidly, they injected radio-labelled insulin into normal and diabetic subjects, and found that the radio-labelled insulin was actually cleared more slowly in diabetics. Then, they begin to experiment with combinations of labelled and unlabeled insulin, and found the phenomenon of competition between labelled and unlabeled insulin. Using the same principles, they described the first radioimmunoassay and this work was considered as the beginning of modern immunoassay (Herzog, 1997).

The use of enzymes for labels in immunochemical reactions dates back to the mid-sixties when enzyme-labelled antibodies were applied to the identification and localization of 
antigens in histological preparations. The use of enzyme labels in an immunoassay was first published in 1971 by a Dutch group ((Herzog, 1997). Although a large variety of other labels (such as fluorescent, phosphorescent, and chemiluminescent dyes) have been applied in immunoassay over the past decades, the enzyme immunoassay (EIA) was still the most popular one.

The application of immunoassays to pesticide residue analysis dates back to 1971, when Ercegovich et al. (1971) described their early work on the detection of pesticides by immunochemical means and indicated the potential usefulness of this method for routine analyses. Following Ercegovich's work, more and more researchers paid their attention to pesticide immunoassay, and this was confirmed by the related publications (Figure 1). At the same time, the American Chemical Society (ACS) had its first symposium on pesticide immunoassay in 1989 during its national meeting. In addition, the Association of Official Analytical Chemists (AOAC) held its first workshop on immunoassay in 1990, and offered an immunoassay workshop at its national meeting again in 1991(Herzog, 1997).

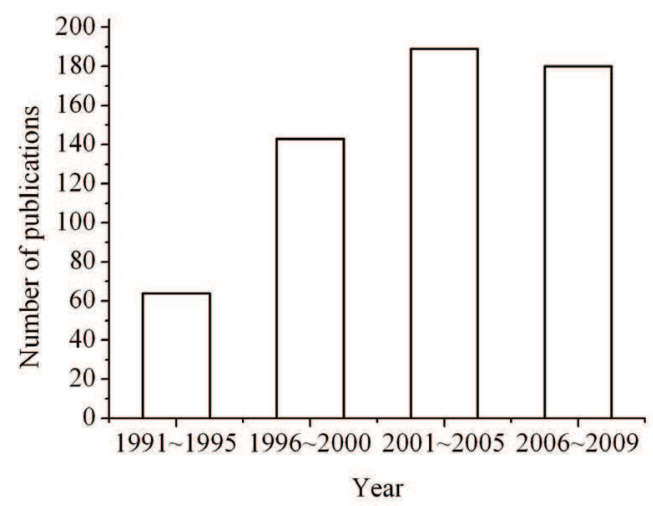

Fig. 1. Number of publications in the topic of "pesticide immunoassay" from 1991 to 2009 (data from "web of knowledge").

\section{Principle of immunoassay}

As stated, an immunoassay is a quantitative or qualitative technique that depends on the reaction between the molecule of interest, "the antigen", and a complementary molecule, "the antibody". An antigen is a molecule that can be recognized by the immune system (immunogenicity) and bound specifically to an antibody (reactogenicity). Molecules with both immunogenicity and reactogenicity are called as "complete antigens"; while molecules that only possess reactogenicity are defined as "incomplete antigens" or "haptens". Pesticide molecules are typical haptens that can induce the immune system to produce antibody only when attached to a large carrier such as a protein. Antibody is the key regent of immunoassay, and can be produced by animal immunization, hybridoma technique or recombinant antibody technique. As to the specific procedure of immunoassay, many kinds of immunoassay format have been developed. However, the competitive immunoassay was the most frequently used one in pesticide immunoassay. In this section, the principle of immunoassay for pesticides detection will be introduced, including the immunogen preparation, antibody production and relevant immunoassay formats. 


\subsection{Immunogen preparation}

The first step of pesticide immunoassay system development was to design and prepare a rational immunogen for antibody production. The typical procedure to prepare immunogen in pesticide immunoassay system development was to link the pesticide molecules to a carrier protein by a coupling spacer (linker) (Figure 2). The site of coupling to the carrier, the length of coupling spacers, the selection of optimized carriers, the coupling procedure as well as the number of haptens bound to one carrier molecule can be of major importance for the sensitivity and selectivity of the resulting antibody (Dankwardt, 2001).

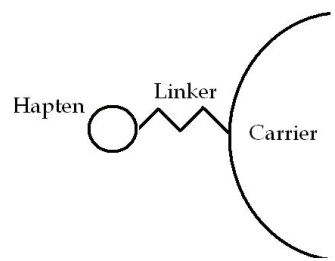

Fig. 2. Sketch map of the immunogen for pesticide specific antibody production.

The desired haptens should be one that hapten-carrier conjugates can induce specific immune response and produce high quality hapten-specific antibodies. While designing/selcting haptens, the most important thing is to ensure the final chemical structure and stereochemistry to be identical or similar with the original haptens (analytical targets). If haptens contain active groups such as $-\mathrm{COOH},-\mathrm{NH}_{2}$ and $-\mathrm{OH}$, they can be directly coupled with the carrier proteins. Otherwise, derivatives of the haptens should be prepared to introduce reactive groups into the structure. In addition, the haptens themselves should possess complicated chemical structures. Generally, most of these desired haptens are characterized by the following aspects: (1) amino group or carboxyl group or both; (2) aromatic compounds; (3) high branch; (4) heteroatom rings (Tong et al., 2007).

Another very important factor is the length of the spacer. If it is too long, the haptens can overlap along the spacer and change their stereo-structures. If it is too short, the carrier protein can cover the hapten and can not produce specific antibody. In addition, the spacer should be non-polar, or, they can change the distribution of the electric density of the hapten (Dankwardt, 2001).

The carrier protein is not only to simply increase the molecular weight of the hapten-carrier conjugate; it can also affect the quality and quantity of immune responses. Bovine serum albumin (BSA), ovalbumin (OVA), keyhole limpet hemocyanin (KLH), and human serum albumin (HSA) are usually used as carriers for the preparation of immunogen. Among these proteins, BSA is the popular one because its physical and chemical stability is higher, no expensive, easily available, more lysine residues and more amino groups. In addition, BSA can also present excellent solubility under various $\mathrm{pH}$ value and ionic strength and react with the targeted haptens in organic solvents such as pyridine and $\mathrm{N}, \mathrm{N}$ dimethylformamide (DMF) (Tong et al., 2007). Generally, the carrier should be heterogenous with the experimental animals, since it is easier to induce strong immune response and to produce high-titer and hapten-specific antibody.

Linking the desired haptens to the carriers is the critical step in immunogen preparation. If the haptens possess active groups such as $-\mathrm{COOH},-\mathrm{OH}$, and $-\mathrm{NH}_{2}$, as described above, they can directly react with the carrier protein, otherwise, structural modifications are required. Based on the chemical and stereo-structure of haptens, various synthetic approaches were 
employed: (1) Carboxyl-containing haptens can be coupled with the carrier proteins using N-hydroxysuccinimide active ester/carbon-diimine or Woodward reagent protocol. (2) Amino-containing haptens can be linked to carriers by employing glutaraldehyde, diisocyanate, halo-nitrobenzene, hiophosgenation, diimine ester, or diazotization protocol. (3) Hydroxyl-containing haptens can be directly connected to the carrier proteins through succinic anhydride or azobenzoic acid protocol. (4) Carbonyl-containing haptens (ketone or aldehyde) are usually connectd to carriers using amino-ox-acetic acid protocol. (5) Homogeneous or heterogeneous difunction reagents can be used to synthesize the immunogen for mercapto-containing haptens (Tong et al., 2007). The general principles of some frequently-used immunogen syntheitc method were outlined in Figure 3.

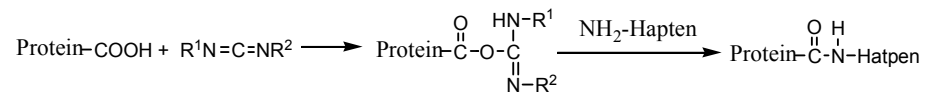

(a) Carbodiimide coupling method

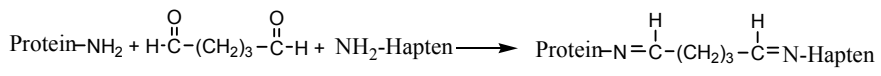

(b) Glutaraldehyde coupling method

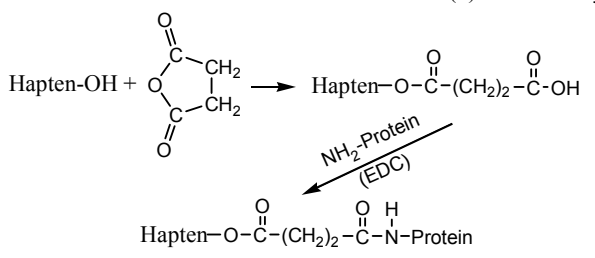

(c) Succinic anhydride coupling method

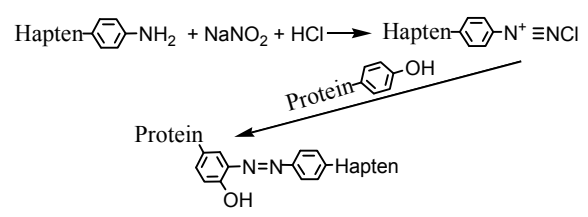

(d) Azide coupling method

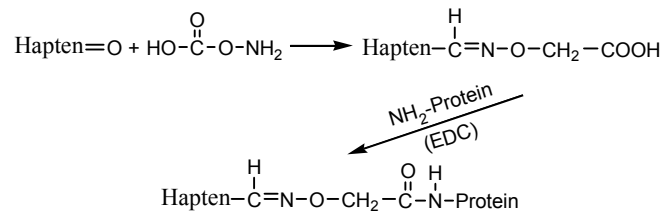

(e) Carboxymrthoxyamine hydrochloride coupling method

Fig. 3. General principles of some frequently-used immunogen syntheitc method (modified after "Tong et al., 2007").

After the artificial hapten-protein conjugate is prepared, a purification step is usually proceeded, since the unreacted hapten molecules, salts and other impurity affect the quality of antibody. Usually, dialysis and chromatography are employed. Comparing the two techniques, dialysis takes long time (usually 2 days or more). However, it can obtain well purified conjugate and the process is simple, which is suitable in various laboratories. Chromatography such as ion-exchange gel chromatography, gel chromatography needs sophisticated equipments and the process is complicated. Anyway, how to select the best purification technique and the specific process is dependent on the substrates. After purification, it is necessary to carry out an identification procedure with two purposes to confirm whether the desired haptens have been successfully connected on the carriers and how many haptens have been bound to one carrier molecule. The most popular technique employed to identify artificial antigen is UV spectrometry. 
As to the issue concerns the optimal number of haptens bound to the carrier protein (i.e. optimal epitope density), highly substituted carriers usually lead to better results. For bovine serum albumin (BSA) molar ratios of $10: 1$ to $20: 1$ (hapten : carrier) are desirable; for larger molecules such as hemocyanin, ratios of $800: 1$ to $1000: 1$ should be obtained. However, very high ratios may reduce immunogenicity because of either the changes in tertiary structure of the protein caused by masking of the essential free amino groups or the removal of critical determinant sites on the carrier by haptenic blocking (Dankwardt, 2001).

\subsection{Antibody production}

\subsubsection{Antibody structure}

Immunoassay is based upon the specific reaction between an antibody and its corresponding antigen. Antibodies are serum glycoprotein of the immunoglobulin class (Ig) produced by the immune system against foreign material such as pathogens or xenobiotics, and bind the target substance with high selectivity and affinity. Although there are five distinct classes of antibody in most higher mammals (IgA, IgD, IgE, IgG, IgM), IgG accounts up approximately $80 \%$ of the total Ig in human serum. In reality, most immunoassay systems rely upon IgG as the major antibody.

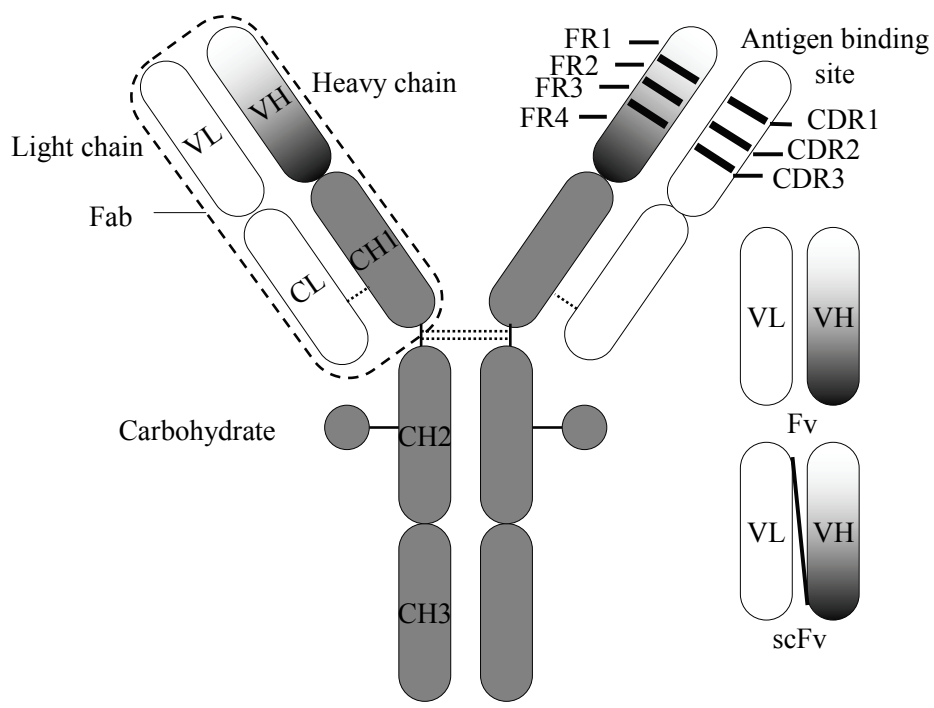

Fig. 4. Structure of antibody and its fragments (modified after "Dankwardt, 2001").

The basic structure of an $\mathrm{Ab}$ molecule is shown in Figure 4. It consists of two identical heavy $(\mathrm{H})$ chains and two identical light $(\mathrm{L})$ chains stabilized and linked by inter- and intra-chain disulfide bonds. The $\mathrm{H}$ - and $\mathrm{L}$-chains are organized into variable and constant regions. The antigen binding site (combining site) is formed by the association of parts of the variable regions of the $\mathrm{H}$ - and L-chains, located at the amino terminal end. The variable regions of both chains are organized into three hypervariable or complementary determining regions (CDRs) separated by four framework regions. The greatest amino acid sequence variation occurs within the CDRs whereas the framework regions are more conserved. It is assumed that the association of the CDR regions forms the combining site. The lower part of the 
molecule contains the last heavy chain domains (crystallizable fragment, Fc) which is responsible for some important biological effector functions such as complement fixation and is not necessary for antigen binding. The whole of the Ig molecule or antibody fragments, F(ab)2 and Fab (antibody fragments containing the antigen binding site(s)) can be used in immunoassay. Moreover, recent research results exhibited that the recombinant antibody fragment, scFv (single-chain Fv fragment) can form intact antigen binding site and can also used for immunoassay.

\subsubsection{Polyclonal antibody production}

Antibody production is conveniently carried out in warm blood animals, e.g. rabbits, sheep, mice or chickens. In this procedure, polyclonal antibodies (pAbs) are obtained from the serum and comprise a mixture of different antibody populations.

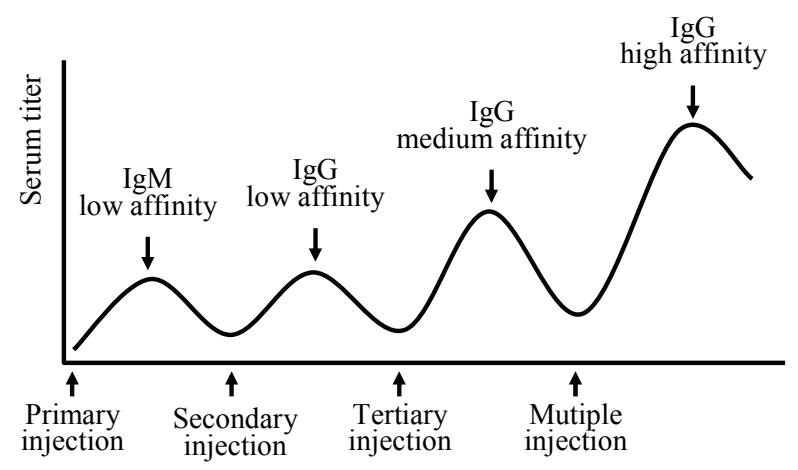

Fig. 5. Kinetics of a typical immune response (modified after "Hefle et al., 2006").

Rabbits are the species almost exclusively used for pesticide pAbs production, principally because they are of a size capable of producing adequate amounts of antibodies, have a relatively long life span, and are relatively easy to handle. Usually, adjuvant is used to improve the immune response to the immunogen. After emulsifying the immunogen by adjuvant, this combination can be injected subcutaneously on the back in at least 4 sites per rabbit with a maximum of $0.25 \mathrm{ml}$ in each site and with the total not to exceed $1 \mathrm{ml}$. The immunization schedule has a decisive influence on the result, and must be rationally designed. Specific recommendations for the interval between primary and booster immunizations are usually not cited. In general, a booster can be considered after the antibody titre has plateaued or begun to decline and 2 to 3 weeks is recommended between each booster injections. In most cases, the endpoint of pAb production should be judged when the antibody titre has reached an acceptable level. This should usually occur after 3 to 5 boosters (Figure 5). Then, the blood of the immunized rabbit can be collected, and serum can be separated for immunoassay development. (Leenaars et al. 1999)

\subsubsection{Monoclonal antibody production}

Monoclonal antibodies (mAbs) consist of a single monospecific antibody population. These antibodies are produced in cell culture by a single hybridoma cell derived from the fusion of B-lymphocytes with myeloma cells. The hybridoma cells can then be propagated almost indefinitely in culture and will continue to produce the antibody of the lymphocyte parent. 
Since an individual lymphocyte produces only a single antibody type, all of the antibody molecules produced by a hybridoma cell line derived from a single hybrid cell are identical and have the same binding properties. Therefore, the hybridoma technology guarantees the unlimited production of $\mathrm{mAbs}$ with constant characteristics.

Figure 6 outlines the protocol of mAbs production. In general, mice are used as Blymphocyte doner for mAbs production. Mice are immunized every 2-3 weeks till a sufficient antibody titer is reached in serum, then immunized mice are euthanized and the spleen removed to use as a source of cells for fusion with myeloma cells. Next, single spleen cells from the immunized mouse are fused with the previously prepared myeloma cells. Fusing antibody-producing spleen cells, which have a limited life span, with cells derived from an immortal tumor of lymphocytes (myeloma) results in a hybridoma that is capable of unlimited growth. After that, hybridoma cells are followed by selection for antigen binding. Then the selected cell line can be used for mAbs production under in vivo or in vitro procedures or combinations thereof. (Marx et al., 1997)

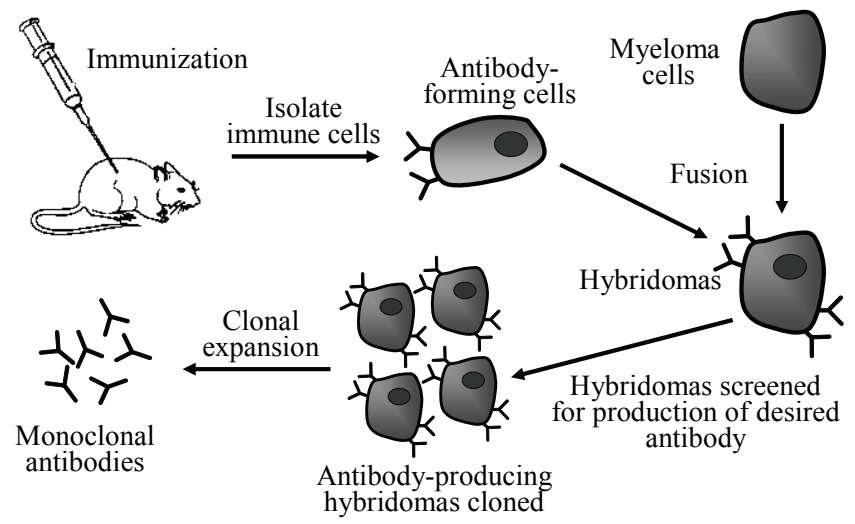

Fig. 6. The protocol of mAbs production (modified after "Michnick \& Sidhu, 2008").

\subsubsection{Recombinant antibody production}

Recently, a third possibility (recombinant antibody ( $\mathrm{rAb}$ ) techniques) for creating antibody has emerged. Here, antibody genes are cloned, introduced and expressed in inexpensive and relatively simple host systems. Although several non-mammalian host systems (yeast, plant and insect cells) have been used to produce rAbs, the most common one is Escherichia coli.

Phage display technology is one of the most widely used approachs for recombinant antibody fragment production. The primary task for making antibody by phage display is to design and construct a phage displayed antibody library. Figure 7 outlines the general protocol of phage displayed antibody library construction. Briefly, antibody fragment gene are constructed by relevant gene operation technology, and then cloning it into a special vector for gene expression in E. coli host. Based on the difference of gene source, antibody library can be classified into naive, immune and synthetic library. Based on the difference of expressed antibody fragment, it can be classified into scFv library, Fab library and so on (Hoogenboom et al., 1998). For more information about antibody library construction, relevant handbooks or monographs, such as "Antibody Phage Display: Methods and Protocols (Aitken, 2009)", can be refered. 


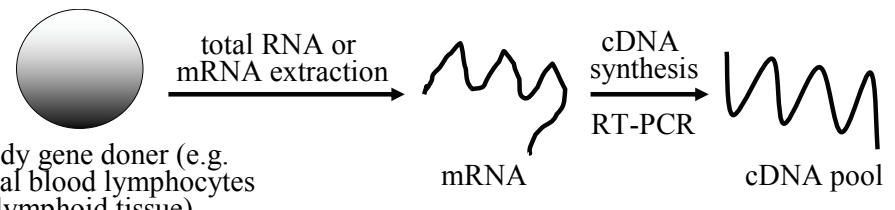

antibody gene doner (e.g. peripheral blood lymphocytes or lymphoid tissue)

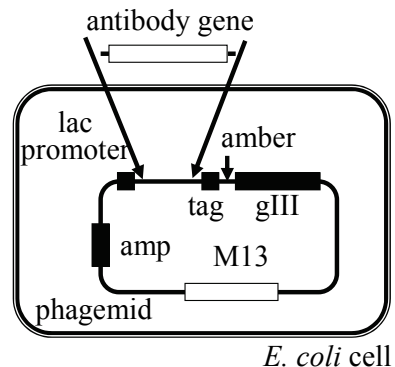

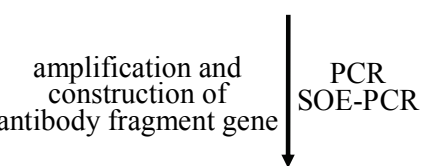

cloning into vector and transferring into $E$. coli host

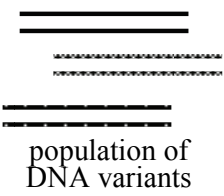

Fig. 7. General protocol of phage displayed antibody library construction.

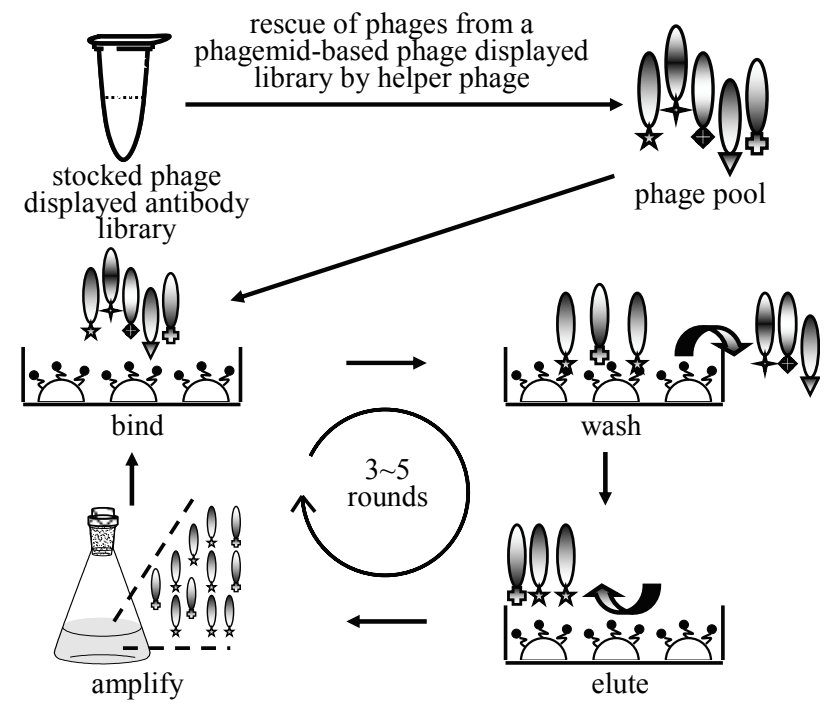

Fig. 8. Isolation of specific antibody fragment from phage-displayed library by biopanning. (modified after "Sheedy, et al., 2007")

After the antibody library is constructed, specific antibody fragment can be isolated from it by biopanning technology. The general procedure of biopanning is outlined in figure 8 . Briefly, antibody phages are firstly rescued from the previously constructed phage displayed antibody libraray by helper phage, and then three to five rounds of "bind-washelute-amplify" procedure are repeated. This process can be operated in solid phase or solution phase, in the former the target are immobilized by adsorption or covalent effect, while in the latter, biotinylated target are used for binding then target-antibody complexes are isolated from solution by immobilized streptavidin. In general, a panning optimization 
experiment is needed for isolating desired antibody fragment (Sheedy, et al., 2007). After this biopanning process, the target specific antibody fragment can be screened by moloclone immunoassay, and those fragments can be used for immunoassay under fusion expression or soluble expression status.

\subsection{Immunoassay formats}

\subsubsection{Immunoassay labels}

Depending on the label, immunoassays are classified into different groups. Radioisotopes are used in RIAs, enzymes in enzyme-linked immunosorbent assays (ELISAs or EIAs), fluorophores in FIAs or PFIAs and chemiluminescent compounds in CLIAs. There are some additional types of immunoassays, but are not commonly used in pesticide analysis. A more detailed description of these immunoassays can be found in relevant reference.

EIAs are most commonly used in pesticide analysis as they avoid the necessity of working with radioactive material and low detection limits can be reached. Simple and cheap photometers which give an extremely rapid measurement capability and long-lasting stability of the colored product make EIAs superior to fluorimetry or luminometry, even though with these methods lower detection limits may be reached. Enzymes used as labels in EIAs including alkaline phosphatase, $\beta$-Galactosidase and peroxidase, of which the peroxidase derived from Horseradish (HRP) is the most commonly used one.

\subsubsection{Traditional pesticide immunoassay formats}

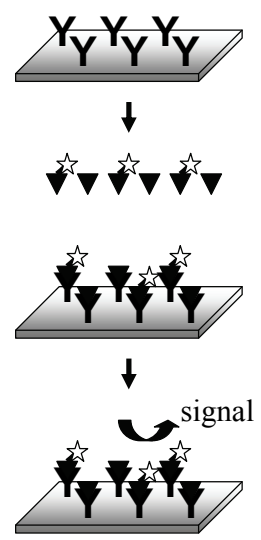

(a)

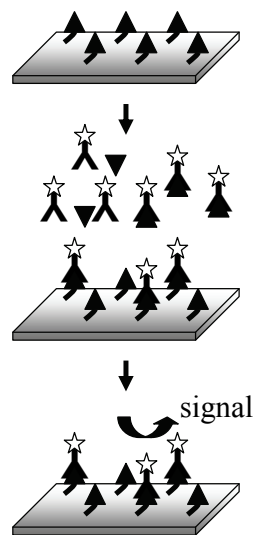

(b)
$\mathbf{Y}$ : antibody

- immobilized hapten

$\boldsymbol{\nabla}:$ free hapten

: labeled hapten

: labeled antibody

Fig. 9. Competitive immunoassay formats.

Traditionally, detection of low-molecular-mass analytes (haptens) such as pesticides in solution must employ competitive immunoassay formats. There are two different competitive formats available for pesticide immunoassay, (1) with immobilized antibody (Figure 9a) and (2) with immobilized coating conjugate (Figure 9b) (Dankwardt, 2001). In variant (1), analyte and labeled analyte (tracer) compete for the free antibody binding sites. After removal of unbound reactants the bound tracer yields a signal. The variant (2) employs an immobilized hapten-carrier conjugate on the solid phase to which analyte and antibody are added. Antibody binds to the free analyte or to the immobilized hapten in certain ration of the 
reactants concentration. If a labeled antibody is used, the amount of antibody bound to the solid phase can be directly determined after a washing step. Alternatively, a secondary labeled antibody may be used to detect the bound antibody. In these competitive immunoassay formats, the signal is inversely proportional to the amount of free analyte in the sample.

In enzyme labled competitive immunoassay, separation of unbound reagent from bound reagent is needed, i.e. heterogeneous assay is performed. While for other labels, homogeneous assay system can be employed. An example for a homogeneous assay system is the polarization fluoroimmunoassay (PFIA) (Eremin \& Samsonova, 1994). PFIA measures the increased polarization of fluorescence when a fluorophore-labeled hapten (tracer) is bound by a specific antibody and the decreased signal when free analyte competes with the tracer for binding. While these assays are easy to carry out and very suitable for automation, they usually show a poorer repeatability than enzyme labled immunoassays.

\subsubsection{Novel immunoassay formats with pesticide detection potential}

Although the traditional competitive immunoassay format have widely applied in pesticide detection, some difficulties also exist for specific target. For example, sensitivity and specificity of immunoassay to pesticide are inferior to macromolecule analytes due to the weakness of immunogenicity. Hence, novel formats have been developed by researchers to overcome those difficulties.

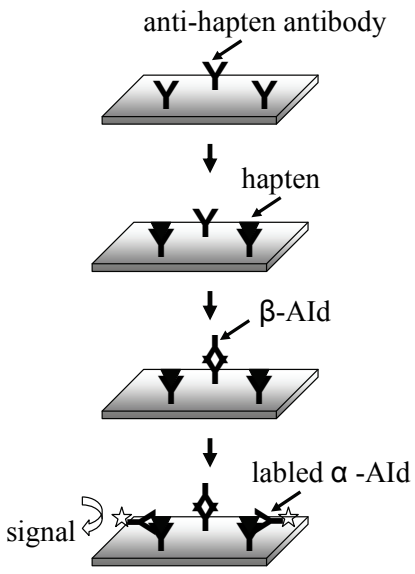

(a)

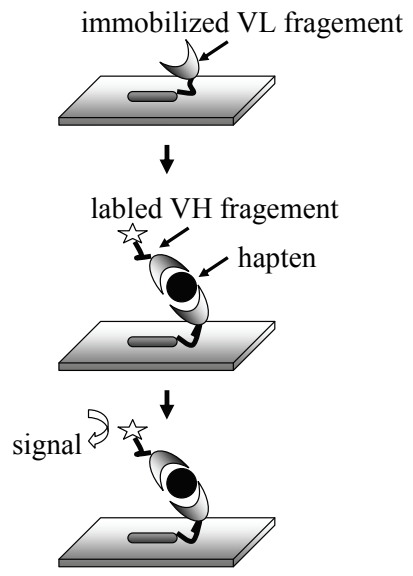

(b)

Fig. 10. Novel immunoassay formats with pesticide detection potential.

The theoretical study of Jackson and Ekins (1986) has demonstrated that noncompetitive immunoassays are superior to competitive immunoassays in terms of sensitivity, precision, kinetics and working range of analyte. Sandwich ELISA is a widely used noncompetitive immunoassay to determine antigen concentration. However, it has a fundamental limit that the antigen to be measured must be large enough to have at least two epitopes to be captured. Hence, it can not be used to measure low-molecular weight compounds, such as pesticides. In order to overcome these drawbacks, novel immunoassay approachs, "idiometric assay" (Figure 10a) and "open sandwich immunoassay" (Figure 10b) were previously proposed. The "idiometric assay" utilizes a-type and $\beta$-type anti-idiotype 
antibody (AId) which have the ability to recognizes different regions of the anti-hapten antibody. The a-AId recognizes an epitope close to the binding site and is not affected by the presence or absence of the analyte but is sterically hindered from binding to the antihapten antibody in the presence of the $\beta$-AId. The $\beta$-AId recognizes an epitope at the unoccupied binding site, which is masked in the presence of the analyte (Barnard \& Kohen, 1990). Meanwhile the "open sandwich immunoassay" is based on the phenomenon of stabilization of an antibody variable region by the bound antigen (Ueda et al., 1996). For more imformation about these two immunoassay formats, relevant paper can be refered. Although they are not widely applied in pesticide detection yet, these two novel formats could be the trend in pesticide immunoassay.

\section{Application of immunoassay in pesticides detection}

Ercegovich (1971) has described his early work on the detection of pesticides by immunochemical means and indicated the potential usefulness of this method for routine analyses in 1971. Since then, more and more immunoassay papers were published annually. Most of those works were targeted to a single specific pesticide, while broad-specificity immunoassay of pesticides could be the tend in the future. In addition, as the great potential of noncompetitive immunoassay format, researchs in this area have been carriing out as well. In this section, literature review of these areas will be provided.

\subsection{Single target immunoassay of pesticides}

Binding specificity is the key feature of all immunoassays. In initial period, the works of pesticide immunoassay were targeted to a single specific pesticide, i.e. single target immunoassay. These works have been summarized elsewhere, such as Hennion \& Barcelo (1998) and Dankwardt (2001). Most of them were just developed in laboratories and only a few of them have been commercially available yet. For example, a commercial immunoassay kit was developed and applied by Watanabe et al. (2007 a) to direct determination of insecticide imidacloprid in fruit juices.

Depending on the conjugate used for immunization and the class of chemicals under investigation, cross-reactivities of the antibdoy with haptens similar to the analyte are frequently observed. For single target immunoassay, cross-reactivities can produce false positive values. This problem could be solved, however, by sophisticated sample preparation technology or (and) antibody purification technology. For example, an antibody for alachlor was found to react very strongly to the sulfonic acid metabolite using an alachlor screening kit, but Aga et al. (1994) solved this problem by using solid-phase extraction (SPE) prior to immunoassy and sequential elution of the two compounds with different organic solvents.

Pesticides are widely used in fruit, vegetable and grain production, hence pesticide residues on/in fruit (fruit juice), vegetable and grain are the most important things to cause food safety problem, which deserve special attention. A variety of pesticides have been determined in those food samples by immunoassay. For example, residues of Carbaryl (Abad \& Montoya, 1995), Azinphos-methyl (Mercader \& Montoya, 1997), Carbofuran (Abad et al., 1997) and Imidacloprid (Watanabe et al., 2007) in fruit juice, and Procymidone (Fernandez-Alab et al., 1995), Fenitrothion (Cho et al., 2004), Isofenphos (Lee et al., 2006) and Iprodione (Watanabe \& Miyake, 2007 b) in vegetables have been detected by immunochemical analysis. In general, direct detection can be applied to liquid food sample, while for solid food sample, the target 
pesticides must be extracted with an organic solvent, such as acetone, ether, petroleum ether, methanol, acetonitrile or hexane. Matrix effects in food samples frequently occur owing to colored extracts or to the content of lipids, proteins or polyphenols that may be coextracted during sample preparation. Hence, the liquid food samples or extracts of solid food sample are usually further diluted with buffer prior to the immunoassay for eliminating matrix effect. For example, in the work of Abad et al, (1995) a monoclonal antibody based immunoassay was applied to direct determination of carbaryl in apple and grape juices. The influence of matrix dilution was investigated using different dilutions of the samples. And their result indicated that, the samples should be diluted at least $1: 5-1: 10$ for proper analysis and the most accurate and precise results were obtained with a dilution of 1:100. In some cases a further cleanup step is needed, in which the analyte of interest is separated from the matrix. Usually, this can be carried out by SPE columns. For example, an ELISA commercial kit was used to quantitate residues of Procymidone at very low levels $(<20 \mathrm{pg} / \mathrm{kg})$ in pepper samples by Amadeo et al. (1995). In this work, samples were extracted with ethyl acetate-sodium sulphate and an aliquot is evaporated to dryness and reconstituted in $10 \mathrm{ml}$ of light petroleum. Then, sample clean up is accomplished by aspirating $2 \mathrm{ml}$ of the light petroleum extract through a silica gel solid phase disposable cartridge. Following aspiration, the sample was eluted with 2 $\mathrm{ml}$ of ethyl ether-petroleum ether $(1: 1)$. The eluted fraction was evaporated and dissolved with sonication in $2 \mathrm{ml}$ of water before immunoassay analysis.

Pesticide residue in soil and water environment is another serious problem. Immunoassay has been used intensively for the determination of pesticides in soil and water sample. For soil sample, matrix effects exist as per the food sample, hence similar sample preparation processes could be suitable. For example, in the work of Johnson et al. (2001), supercritical fluid extraction (SFE) was coupled with a commercial semi-quantitative enzyme-linked immunosorbent assay for detection of polychlorinated biphenyls in an oily soil matrix. While for water sample, direct detection can be applied as per the liquid food sample, but sample dilution is usually not required.

The third application of pesticide immunoassay is biomonitoring, which involoves the measurement of a parent chemical and/or metabolites or a product of its reaction with cellular components in selected tissues, body fluids such as blood, milk, urine or sweat, or expired breath of an exposed individual. Most immunoassays for pesticides are sensitive enough for biomonitoring, and many analytes could be determined without any sample preparation except for dilution with water or buffer. As in the work of Chuang et al. (2005), for quantitative measurement of 2,4-dichlorophenoxyacetic acid (2,4-D) in human urine by immunoassay, samples were diluted $(1: 5)$ with phosphate-buffered saline containing $0.05 \%$ Tween and $0.02 \%$ sodium azide. Result indicated that, recovery rates of 2,4-D in spiked urine samples were over $70 \%$.

Usually, after immunoassay system development, a validation of the results obtained by immunoassay should be carried out. To a limited extent this can be done by immunoassay itself. Dilution of the samples as well as spiking of the authentic sample with known amounts of the contaminant can be used to check whether the matrix interferes with the immunoassay. But for more strict, an immunoassay should be validated by a different established method like high-performance liquid chromatography (HPLC), gas chromatography (GC) or gas chromatography/mass spectrometry (GC/MS). Many groups have used this approach and have usually obtained correlation coefficients of $>0.9$. Often a slight overestimation of the immunoassay in comparison with HPLC or GC is observed owing to cross-reactivities of the antibody or matrix effects. (Dankwardt, 2001) 


\subsection{Broad-specificity immunoassay of pesticides}

As stated, immunoassays have been developed for effectively measuring individual pesticides; however, it is now more desirable to use the technique to identify more than one target simultaneously. In another word, there is a need now to increase sample throughput and to screen samples for more than one analyte per text (Spinks, 2000). To achieve this it is possible to raise mumberous antibodies that recognise individual targets and incorporate all the antiboies into a single test. However, a more economical alternative is to raise a single antibody that is able to determine several analytes in one test, which is called a broadspecifcity antibody.

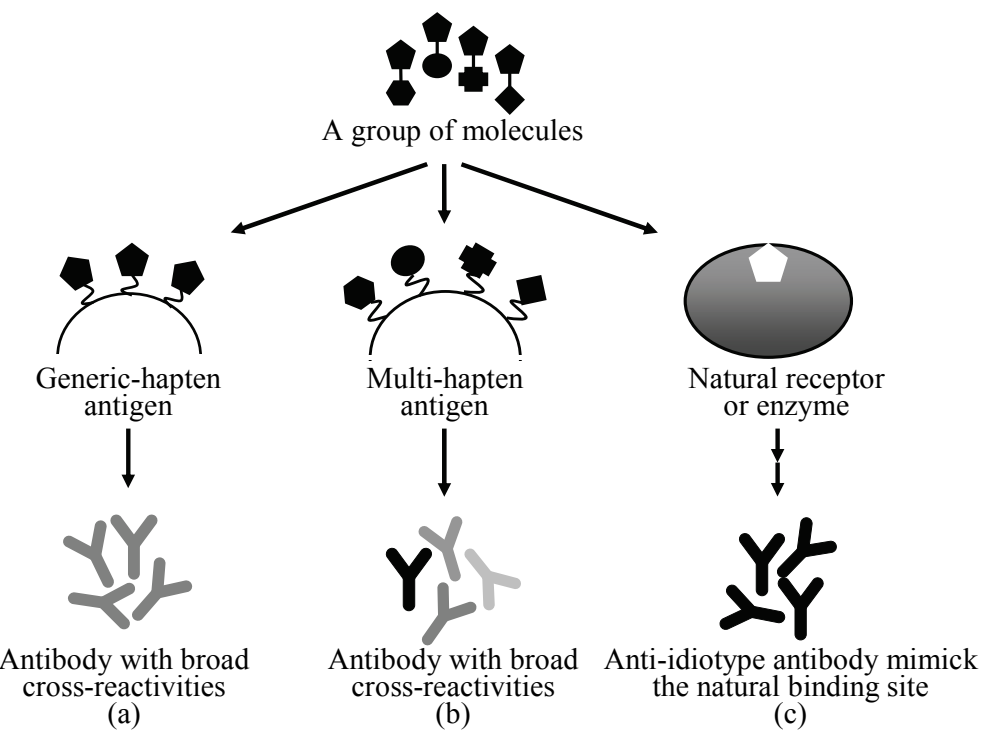

Fig. 11. Strategies for broad-specificity antibody production.

A valid strategy for broad-specificity antibody production is to synthesize generic hapten based on the similar structure of a group molecules, and then prepare an antibody with broad cross reactivities (Figue 11 (a)). Examples of broad specifity antibody production by this strategy are summarized in table 1. As in the work of our group (Liang et al., $2008 \mathrm{a}, \mathrm{b}$ ), three generic haptens of O,O-dimethyl organophosphorus pesticides with different spacer-arms were synthesized for broad-specifcity antibody production, then a general and broadspecificity enzyme-linked immunosorbent assay was developed for malathion, dimethoate, phenthoate,phosmet, methidathion, fenitrothion, methyl parathion and fenthion. The haptens were conjugated to bovineserum albumin (BSA) for immunogens and to ovalbumin (OVA) for coating antigens. Rabbits were immunized with the immunogens and six polyclonal antisera were produced and screened against each of the coating antigens using competitive indirect enzyme-linkedimmunosorbent assay for selecting the proper antiserum. The antibody-antigen combination with the most selectivity for malathion was further optimized and tested for tolerance to cosolvent, $\mathrm{pH}$ and ionic strength changes. The $\mathrm{IC}_{50}$ values, under optimum conditions, were estimated to be $30.1 \mu \mathrm{g} \mathrm{L} \mathrm{L}^{-1}$ for malathion, $28.9 \mu \mathrm{g} \mathrm{\textrm {L } ^ { - 1 }}$ for dimethoate, $88.3 \mu \mathrm{g}$ $\mathrm{L}^{-1}$ for phenthoate, $159.7 \mu \mathrm{g} \mathrm{L}^{-1}$ for phosmet, $191.7 \mu \mathrm{g} \mathrm{L}^{-1}$ for methidathion, $324.0 \mu \mathrm{g} \mathrm{L}^{-1}$ for fenitrothion, $483.9 \mu \mathrm{g} \mathrm{L}-1$ for methyl parathion, and $788.9 \mu \mathrm{g} \mathrm{L} \mathrm{L}^{-1}$ for fenthion. Recoveries of 
malathion, dimethoate, phenthoate, phosmet and methidathion from fortified Chinese cabbage samples ranged from $77.1 \%$ to $104.7 \%$. This assay can be used in monitoring studies for the multi-residue determination of $\mathrm{O}, \mathrm{O}$-dimethyl organophosphorus pesticides.

\begin{tabular}{|c|c|c|}
\hline Target Pesticides & Antibody & References \\
\hline organophosphorus pesticides & $\mathrm{mAb}$ & Wang et al., (2010) \\
\hline $\begin{array}{l}\mathrm{O}, \mathrm{O} \text {-dimethyl } \\
\text { organophosphorus pesticides }\end{array}$ & $\mathrm{pAb}$ & Liang et al., (2008 a, b) \\
\hline $\begin{array}{l}\mathrm{O}, \mathrm{O} \text {-dimethyl } \\
\text { organophosphorus pesticides }\end{array}$ & $\mathrm{mAb}$ & Liu et al., (2009) \\
\hline $\begin{array}{l}\mathrm{O}, \mathrm{O} \text {-diethyl organophosphorus } \\
\text { pesticides }\end{array}$ & $\mathrm{pAb}$ & Xu et al., (2009 a) \\
\hline $\begin{array}{l}\text { O,O-diethyl organophosphorus } \\
\text { pesticides }\end{array}$ & $\mathrm{mAb}$ & Jang et al., (2002) \\
\hline pyrethroid insecticides & $\mathrm{pAb}$ & Kuang et al., (2009) \\
\hline type I pyrethroid insecticides & $\mathrm{pAb}$ & $\begin{array}{l}\text { Watanabe et al., (2001); } \\
\text { Zhang et al.,(2010) }\end{array}$ \\
\hline type II pyrethroid insecticides & $\mathrm{pAb}$ & $\begin{array}{l}\text { Lee et al., }(1998 \mathrm{a}, \mathrm{b}) ; \\
\text { Mak et al., }(2005) ; \\
\text { Zhang et al., (2010) }\end{array}$ \\
\hline benzoylphenylurea insecticides & $\mathrm{pAb}$ & Wang et al., (1998) \\
\hline triazine & $\mathrm{mAb}$ & Bertoncini et al., (2003). \\
\hline
\end{tabular}

Table 1. Examples of broad-specifcity antibody production by "generic hapten" strategy.

Another approach for broad-specificity antibody production is preparing a multi-hapten antigen for antibody produciton (Figue 11 (b)). For example, a multi-determinant artificial antigen was prepared by haptens of four pesticides (chlorpyrifos, triazophos, carbofuran and parathion methyl) conjugating to the carrier protein BSA in turn. Then, male New Zealand white rabbits were immunized with this multi-determinant immunogen to produce the polyclonal antibodies, which can react with the four pesticides. Characterization studies of the polyclonal antibodies showed that it has high affinity and specificity to the four relative pesticides. At last, an indirect competitive enzyme-linked immunosorbant assay was developed for multi-residue determination. The $\mathrm{IC}_{50}$ value for the four pesticideswas $0.290,0.065,0.582$ and $2.824 \mu \mathrm{g} \mathrm{ml}^{-1}$, with the detection limit $\left(\mathrm{IC}_{10}\right)$ of $0.022,0.005,0.015$ and $0.115 \mu \mathrm{g} \mathrm{ml}-1$ for carbofuran, triazophos, chlorpyrifos and parathion methyl, respectively (Wang et al., 2007).

The third strategy for broad-specificity antibody production is relied on the concept of $\beta$ type anti-idiotype antibody (Figue 11 (c)). In nature, there are some receptors or enzyme molecules can bind groups of structurally related compounds. If these naturally occurring binding can be mimicked by $\beta$-type anti-idiotype antibody, a broad-specificity antibody will be obtained. For example, cutinase can bind to kinds of carbamates and organophosphate pesticides, based on this point, a broad-specificity immunoassay of organophosphate pesticides was developed by Ward et al. (1999). After preparation of a monoclonal Ab against cutinase, this antibody was used as antigen, an anti-idiotype antibody (monoclonal antibody) which mimicks the active site of cutinase was acquired. Results indicated that this anti-idiotype antibody was able to bind the organophosphate pesticides, chlorfenvinphos, ethyl paraoxon, tetrachlorfenvinphos and demeton-s-methyl. 


\subsection{Noncompetitive immunoassay of pesticides}

As stated above, it was widely accepted that noncompetitive immunoassays are superior to the competitive counterparts. Example of noncompetitive immunoassay of pesticides was reported by Anfossi et al. (2004). This work highlights the characteristics of a general method of performing noncompetitive immunoassays for low-molecular-mass analytes, which was developed and applied to 1,1,1-trichloro-2,2-bis(4-chlorophenyl)ethane (DDT) determination in aqueous samples. The method is based on the separation of the analyte-bound antibody from the excess of the free antibody by a chromatographic step, followed by the dissociation of the complex and the capture of the previously bound antibody on a solid phase. The measured signal is linearly correlated to the concentration of the complex and, consequently, to the analyte concentration. The $3 \sigma$ limit of detection (LOD, $8 \mathrm{ng} \mathrm{L}^{-1}$ ) obtained by the above method enabled decidedly improve the sensitivity of the corresponding enzyme-linked immunosorbant assay and of all reported immunoassays for DDT. In addition, by applying this new format, even if a very selective antibody was used, a broad selectivity could be observed, which allowed DDT + DDD+ DDE to be determined instead of only p, $\mathrm{p}^{\prime}$-DDT as in the assay performed with the same antibody. Further, real water samples were validated in a recovery test. Very good recovery rates were obtained, confirming the validity of the proposed method to accurately determine the total DDT content in water.

From the example above mentioned, it is known that, development of noncompetitive immunoassay for small molecules such as pesticide is a complex task. It was due to small molecules present single epitope (monovalent antigens), and hence non-competive sandwich immunoassay could not be applied in small molecules as per the large molecules such as protein. Idiometric assay (Figure 8a) and open sandwich immunoassay (Figure 8b) are novel noncompetitive immunoassay formats with small molecules detection potential. The former format has sucessfully applied in the detection of small molecules such as estradiol (Barnard \& Kohen, 1990; Barnard et al., 1991; Mares et al., 1995), progesterone (Barnard et al., 1995), UDCA 7-NAG (a bile acid metabolite) (Kobayashi et al., 2000; Kobayashi et al., 2003 a), 11-deoxycortisol (Kobayashi et al. 2003 b) and cortisol (Niwa et al., 2009). And the latter has successfully applied in the detection of gibberellin (Lee et al., 2008), benzaldehyde (Shirasu et al., 2009), zearalenone (Suzuki et al., 2007) and 11-Deoxycortisol (Ihara et al., 2009). Although they are not widely applied in pesticide detection yet, thess two novel formats could be the trend in pesticide immunoassay. In our recently unpublished work, a noncompetitive immunoassay based on anti-idiotype antibodies was developed for $\mathrm{O}$, O-dimethyl organophosphorus pesticides detection. Positive and negative primary antibodies were affinity purified and used for biopanning of anti-idiotype antibody (AId) from phage displayed antibody library. After three round of panning, three a-AId and nine $\beta$-AId clones were achieved. At last, based on clones D11 and B9 (identified as $\beta$-AId and aAId respectively), a broad-specificity noncompetitive immunoassay of $\mathrm{O}$, O-dimethyl organophosphorus pesticides was developed.

\section{Conclusion and future outlook}

Immunoassay technique provides a simple, powerful and inexpensive method for pesticide analysis, and has become a popular research field. Coupled with the development of relevant theory and technology, some more convenient immunoassay techniques have developed and successfully applied in pesticide detection. 
Dipstick immunoassay is a typical example of convenient immunoassay format. Its main advantage is easy to use without sample prepatation, just by dipping the strips into the water. The dipstick techniques involve first the competitive immuno-reaction and then the colour development. Test strips are usually prepared by applying a coating of primary antibody and then incubating with the specific antibody. Once the strip is prepared, the immunoassay dipstick is dipped into the solution and the enzyme tracer, and then incubated a certain time. The enzyme substrate is added and incubated if necessary. The dipstick is then removed from the solution and quantitative measurements can be obtained photometrically (Henion \& Barcelo, 1998). Another strip format has been described, based on gold nanoparticles (GNPs), and is described below. Such a system was described for the determination of dichlorodiphenyltrichloroethane (DDT): an organochlorine pesticide. GNPs with definite size were synthesized and conjugated to anti-DDT antibodies (IgY), which served as the detecting reagent. DDA-BSA conjugate (antigen) was immobilized on to nitro cellulose (NC) membrane containing strip. GNPs conjugated anti-DDT antibodies were treated with different concentrations of free DDT ranging from $0.7 \mathrm{ng} \mathrm{ml}^{-1}$ to $1000 \mathrm{ng} \mathrm{ml}^{-1}$ to form an immunocomplex. This immunocomplex solution was further reacted with DDABSA conjugate immobilized NC membrane containing strips by dipping the strip in the immunocomplex solution. The free GNPs conjugated anti-DDT antibodies present in the immunocomplex solution were targeted for competitive binding with immobilized DDABSA on NC membrane containing strip. Depending on the concentration of free DDT in the sample the binding of GNPs conjugated anti-DDT antibodies to the immobilized DDA-BSA varied and was detected by the development of red color (due to gold nanoparticles) in the detection zone of NC membrane containing strips. The intensity of color development was inversely proportional to the DDT concentration with maximum intensity at zero DDT concentration. The lowest detection limit of DDTwas determined to be $27 \mathrm{ng} \mathrm{ml}^{-1}$ with the optimized conditions (Lisa et al., 2009).

Immunosensor is the most sophisticated immunoassay format to date. It is designed so that the formation of the immune complex on the transducer surface is directly determined by measuring the physical changes (electrical or optical) induced by the binding reaction. Either the antibody or the antigen is immobilized on the transducer carrier surface forms a sensing device and allows reacting with the complementary antigen or antibody to form an immune complex. This formation alters the physical properties of the surface. Depending upon the transducer technology employed, immunosensors are broadly classified into optical, piezoelectric (PZ), electrochemical and micromechanical. Immunosensors have great potential to become costeffective, sensitive devices for on-site monitoring of pesticide pollutants. Recent developments in immunosensors for pesticides detection have been summarized by Suri et al. (2009).

However, the progress of development of new immunoassays and related immunotechnologies is still limited by the availability of antibodies with the desired affinities and specificities for given applications. Efforts are still to be made for developing antiboies for both common and new pesticides. As stated, the first and critical step for developing immunoassay system for pesticide detection is to design and prepare a rational hapten molecule. The importance of careful hapten design during immunoassay development can never be underestimated. Traditionally, however, design of hapten molecules in immunoassay development is primarily based on trial and error. For example, in order to generate a desired antibody with high affinity and specificity, a series of immunogen were designed and used to immunize animals, and then immunoassay methods were used to 
screen for the best antibody. These procedures are time-consuming and very laborious, and sometimes the obtained antibodies lack the required features to develop a useful immunoassay. Recently, the computer-assisted molecular modelling (CAMM) provides a useful tool for hapten design. CAMM can provide insights into molecular structure and biological activity that are difficult or otherwise impossible to obtain, and it has been successfully applied in rational hapten design. For example, Julicher et al. (1995) applied CAMM to investigate the structure of the hapten and evaluated the influence of spacer arm on hapten conformation and electronic nature as compared with the analyte. A suitable molecule based on CAMM results was selected for immunization, and two polyclonal antibodies were raised; one was selective to 2,4,6-trinitrotoluene, and the other was able to recognize important structurally related compounds at low concentrations $\left(2-1000 \mu \mathrm{g} \mathrm{L}^{-1}\right)$. More details about application of CAMM to rational hapten design have been reviewed by $\mathrm{Xu}$ et al. $(2009 \mathrm{~b})$. It is believed that, CAMM will be a useful and potential tool in helping develop immunoassays with better sensitivity and specificity in the future.

Continued academic and industrial research offers additional less traditional methodologies for production of binding species (molecularly imprinted polymers, aptamers) against pesticides. Molecularly imprinted polymers (MIPs) are synthetic polymeric materials with specific recognition sites complementary in shape, size and functional groups to the template molecule, involving an interaction mechanism based on molecular recognition. These recognition sites mimic the binding sites of biological entities such as antibodies and enzymes, and the molecularly imprinted polymers have been widely recognised as synthetic and robust alternatives to antiboies ("plastibodies"). While, aptamers are single stranded DNA or RNA ligands which can be selected for different targets starting from a huge library of molecules containing randomly created sequences. The selected aptamers can bind to their targets with high affinity and even discriminate between closely related targets, hence it can also be considered as a valid alternative to antibodies.

The first successful emulation of a biological immunoassay by using molecularly imprinted polymers (pseudo-immunoassay) was early reported by Mosbach's group in 1993 (Vlatakis et al., 1993). Up to now, molecularly imprinted polymers based immunoassays have been successfully applied to the detection of pesticdes, such as 2,4-D (Lu et al., 2007; Vandevelde et al., 2007), Atrazine (Prasad et al., 2007), Parathion (Li et al., 2005) and so on. While, aptamers that recognize small molecules, such as amino acids, antibiotics, organic dyes and so on, have been successfully obtained (Famulok, 1999). In addation, aptamer based biosensor system has been developed and appiled to the detection of cocaine, adenosine, and so on (Lee et al., 2010). It is believed that, these alternatives of antibodies will be critical materials for rapid detection of pesticides in the future.

\section{References}

Abad, A.; Moreno, M. J. \& Montoya, A. (1997). A monoclonal immunoassay for carbofuran and its application to the analysis of fruit juices. Analytica Chimica Acta, 347(1-2), $103-110$

Abad, A. \& Montoya, A. (1995). Application of a monoclonal antibody-based ELISA to the determination of carbaryl in apple and grape juices. Analytica Chimica Acta, 311(3), 365-370. 
Aga, D. S.; Thurman, E. M. \& Pomes, M. L. (1994). Determination of alachlor and its sulfonic acid metabolite in water by solid-phase extraction and enzyme-linked immunosorbent assay, Anal. Chem., 66(9), 1495-1499.

Aitken, R. (2009). Antibody phage display: methods and protocols, Second edition, Springer , New York.

Anfossi, L.; Giraudi, G.; Tozzi, C.; Giovannoli, C.; Baggiani, C. \& Vanni, A. (2004). Development of a noncompetitive immunoassay for monitoring DDT, its metabolites and analogues in water samples. Anal. Chim. Acta, 506(1), 87-95.

Barnard, G.; Karsiliyan, H. \& Kohen, F. (1991). Idiometric assay, the 3rd way - a noncompetitive immunoassay for small molecules. American Journal of Obstetrics and Gynecology, 165(6), 1997-2000.

Barnard, G. \& Kohen, F. (1990). Idiometric assay - noncompetitive immunoassay for small molecules typified by the measurement of estradiol in serum. Clinical Chemistry, 36(11), 1945-1950.

Barnard, G.; Osher, J.; Lichter, S.; Gayer, B.; Deboever, J. \& Limor, R. (1995). The measurement of progesterone in serum by a noncompetitive idiometric assay. Steroids, 60(12), 824-829.

Bertoncini, N. D.; Pichon, V. \& Hennion, M. C. (2003). Experimental comparison of three monoclonal antibodies for the class-selective immunoextraction of trizaines: Correlation with molecular modeling and principal component analysis studies. J. Chromatogr. A, 999(1-2), 3-15.

Chuang, J. C.; Van Emon, J. M.; Durnford, J. \& Thomas, K. (2005). Develoment and evaluation of an enzyme-linked immunosorbent assay (ELISA) method for the measurement of 2,4-dichlorophenoxyacetic acid in human urine. Talanta, 67(3), 658666.

Cho, Y. A.; Seok, J. A.; Lee, H. S.; Kim, Y. J.; Park, Y. C. \& Lee, Y. T. (2004). Synthesis of haptens of organophosphorus pesticides and development of immunoassays for fenitrothion. Analytica Chimica Acta, 522(2), 215-222.

Dankwardt, A. (2001). Immunochemical assays in pesticide analysis, In: Encyclopedia of Analytical Chemistry, Meyers, R. A. (Ed.), 1-26, Wiley: Chichester, UK.

Famulok, M. (1999). Oligonucleotide aptamers that recognize small molecules. Curr. Opin. Struct. Biol., 9(3), 324-329.

Fernandez-Alba, A. R.; Valverde, A.; Aguera, A.; Contreras, M. \& Rodriguez, D. (1995). Determination of procymidone in vegetables by a commercial competitive inhibition enzyme immunoassay. Analytica Chimica Acta, 311(3), 371-376.

Ercegovich, C. D. (1971). Analysis of pesticide residues: Immunological techniques, In: Pesticides Idetntification, Biros, F. J. (Ed.), 162-178, American Chemical Society, Washington, DC.

Eremin, S. A. \& Samsonova, J. V. (1994). Development of polarization fluoroimmunoassay for the detection of s-Triazine herbicides. Analytical Letters, 27(15), 3013-3025.

Hefle, S. L.; Yeung, J. \& Helm, R. (2006). Antibodies, In: Detecting allergens in food, Koppelman, S. J. \& Hefle, S. L., (Ed.), 65-78, Woodhead Publishing Limited, Cambridge England.

Hennion, M. C. \& Barcelo, D. (1998). Strengths and limitations of immunoassays for effective and efficient use for pesticide analysis in water samples: A review. Anal. Chim. Acta, 362(1), 3-34. 
Herzog, D. P. (1997). Immunoassays for environmental contaminants (Pesticides) in food and water, Proceedings of Food Contaminants Workshop, pp. 1-26, AOAC, Washington, DC.

Hoogenboom, H. R.; Bruine, A. P.; Hufton, S. E.; Hoet, R. M.; Arends, J. W. \& Roovers, R. C. (1998). Antibody phage display technology and its applications. Immunotechnology, $4(1), 1-20$.

Ihara, M.; Suzuki, T.; Kobayashi, N.; Goto, J. \& Ueda, H. (2009). Open-sandwich enzyme immunoassay for one-step noncompetitive detection of corticosteroid 11deoxycortisol. Anal Chem, 81(20), 8298-8304.

Jackson, T.M.\& Ekins, R.P. (1986). Theoretical limitations on immunoassay sensitivity. J. Immunol. Methods, 87(1), 13-20.

Jang, M. S.; Lee, S. J.; Xue, X.; Kwon, H. M.; Ra, C. S.; Lee, Y. Y. \& Chung T. (2002). Production and characterization of monoclonal antibodies to a generic hapten for class-specific determination of organophosphorus pesticides. Bull. Korean Chem. Soc., 23(8), 1116-1120.

Johnson, J. C.; Van Emon, J. M.; Clarke, A. N. \& Wamsley, B. N. (2001). Quantitative ELISA of polychlorinated biphenyls in an oily soil matrix using supercritical fluid extraction. Analytica Chimica Acta, 428(2), 191-199.

Julicher, P.; Mussenbrock, E.; Renneberg, R. \& Cammann, K. (1995). Broadening the antibody specificity by hapten design for an enzyme-linked immunoassay as an improved screening method for the determination of nitroaromatic residues in soils. Anal. Chim. Acta 315(3), 279-287.

Kobayashi, N.; Iwakami, K.; Kotoshiba, S.; Niwa, T.; Kato, Y. \& Mano, N. (2006). Immunoenzymometric assay for a small molecule,11-deoxycortisol, with attomolerange sensitivity employing an scFv-enzyme fusion protein and anti-idiotype antibodies. Analytical Chemistry, 78(7), 2244-2253.

Kobayashi, N.; Kubota, K.; Oiwa, H.; Goto, J.; Niwa, T. \& Kobayashi, K. (2003 a). Idiotypeantiidiotype-based noncompetitive enzyme-linked immunosorbent assay of ursodeoxycholic acid 7-N-acetylglucosaminides in human urine with subfemtomole range sensitivity. Journal of Immunological Methods, 272(1-2), 1-10.

Kobayashi, N.; Oiwa, H.; Kubota, K.; Sakoda, S. \& Goto, J. (2000). Monoclonal antibodies generated against an affinity-labeled immune complex of an anti-bile acid metabolite antibody: an approach to noncompetitive hapten immunoassays based on anti-idiotype or anti-metatype antibodies. Journal of Immunological Methods, 245(1-2), 95-108.

Kobayashi, N.; Shibusawa, K.; Kubota, K.; Hasegawa, N.; Sun, P. \& Niwa, T. (2003 b). Monoclonal anti-idiotype antibodies recognizing the variable high-affinity antibody against 11-deoxycortisol. Production, characterization and application to a sensitive noncompetitive immunoassay. Journal of Immunological Methods, 274(1-2), 63-75.

Kuang, H.; Wu, Y. N.; Hou, X. L.; Miao, H.; Zhang, G.; Shen, J. Z. \& Xu, C. L. (2009). Synthesis of derivatives and production of antiserum for class specific detection of pyrethroids by indirect ELISA. Int. J. Environ. An. Ch., 89(6), 423-437.

Lee, J. H.; Yigit, M. V.; Mazumdar, D. \& Lu, Y. (2010). Molecular diagnostic and drug delivery agents based on aptamer-nanomaterial conjugates. Advanced Drug Delivery Reviews, 62(6), 592-605. 
Lee, N.; Beasley, H. L. \& Skerritt, J. H. (1998 a). Development of immunoassays for type II pyrethroids. 1. Hapten design and application to heterologous and homologous assays. J. Agric. Food Chem., 46(2), 520-534.

Lee, N.; Beasley, H. L. \& Skerritt, J. H. (1998 b). Development of immunoassays for type II pyrethroids. 2. Assay specificity and application to water, soil and grain. J. Agric. Food Chem., 46(2), 535-546.

Lee, W. Y.; Lee, E. K.; Kim, Y. J.; Park, W. C.; Chung, T. \& Lee, Y. T. (2006). Monoclonal antibody-based enzyme-linked immunosobent assays for the detection of the organophosphorus insecticide isofenphos. Analytica Chimica Acta, 557(1-2), 169-178.

Lee, Y.; Asami, T.; Yamaguchi, I.; Ueda, H. \& Suzuki, Y. (2008). A new gibberellin detection system in living cells based on antibody V-H/V-L interaction. Biochemical and Biophysical Research Communications, 376(1), 134-138.

Leenaars, P. P. A. M.; Hendriksen, C. F. M.; Leeuw, W. A.; Carat, F.; Delahaut, P.; Fischer, R.; Halder, M.; Hanly, W. C.; Hartinger, J.; Hau, J.; Lindblad, E. B.; Nicklas, W.; Outschoorn, I. M. \& Stewart-Tull, D. E. S. (1999). The production of polyclonal antibodies in laboratory animals, The Report and Recommendations of ECVAM Workshop 35, pp. 79-102. ECVAM, Ispra, Italy.

Li, C.; Wang, C.; Guan, B.; Zhang, Y. \& Hu, S. (2005). Electrochemical sensor for the determination of parathion based on p-tert-butylcalix[6]arene-1,4-crown-4 sol-gel film and its characterization by electrochemical methods. Sens. Actuators B: Chem., 107(1), 411-417.

Liang, Y.; Liu, X. J.; Liu, Y.; Yu, X. Y. \& Fan, M. T. (2008 a). Synthesis of three haptens for the class-specific immunoassay of O,O-dimethyl organophosphorus pesticides and effect of hapten heterology on immunoassay sensitivity. Analytica Chimica Acta, 615(2), 174-183.

Liang, Y.; Liu, Y.; Zhu, J. F.; Fan, M. T. \& Liu, X. J. (2008 b). Production of broad specificity anti-methoxyorganophosphorus pesticides antibody. Chinese Journal of Analytical Chemistry, 36(5), 647-652.

Lisa, M.; Chouhan, R. S.; Vinayaka, A. C.; Manonmani, H. K. \& Thakur, M. S. (2009). Gold nanoparticles based dipstick immunoassay for the rapid detection of dichlorodiphenyltrichloroethane: An organochlorine pesticide. Biosensors and Bioelectronics, 25(1), 224-227.

Liu, Y.; Lou, Y.; Xu, D.; Qian, G.; Zhang, Q.; Wu, R.; Hu, B. \& Liu, F. (2009). Production and characterization of monoclonal antibody for class-specific determination of $\mathrm{O}, \mathrm{O}-$ dimethyl organophosphorus pesticides and effect of heterologous coating antigens. Microchemical Journal, 93(1), 36-42.

Lu, C. H.; Zhou, W. H.; Han, B.; Yang, H. H.; Chen, X. \& Wang, X. R. (2007). Surfaceimprinted core-shell nanoparticles for sorbent assays. Anal. Chem., 79(14), 54575461.

Mak, S. K.; Shan, G.; Lee, H. J.; Watanabe, T.; Stoutamire, D. W.; Gee, S. J. \& Hammock, B. D. (2005). Development of a class selective immunoassay for the type II pyrethroid insecticides. Analytica Chimica Acta, 534(1), 109-120.

Mares, A.; Deboever, J.; Osher, J.; Quiroga, S.; Barnard, G. \& Kohen, F. (1995). A direct noncompetitive idiometric enzyme-immunoassay for serum estradiol. Journal of Immunological Methods, 181(1), 83-90. 
Marx, U.; Embleton, M. J.; Fischer, R.; Gruber, F. P.; Hansson, U.; Heuer, J.; Leeuw, W. A.; Logtenberg, T.; Merz, W.; Portetelle, D.; Romette, J. L. \& Straughan, D. W. (1997). Monoclonal antibody production, The Report and Recommendations of ECVAM Workshop 23, pp. 121-137. ECVAM, Ispra, Italy.

Mercader, J. V. \& Montoya, A. (1997). A monoclonal antibody-based ELISA for the analysis of azinphos-methyl in fruit juices. Analytica Chimica Acta, 347(1-2), 95-101.

Michnick, S. W. \& Sidhu, S. S. (2008). Submitting antibodies to binding arbitration. Nature Chemical Biology, 4(6), 326-329.

Niwa, T.; Kobayashi, T.; Sun, P.; Goto, J.; Oyama, H. \& Kobayashi, N. (2009). An enzymelinked immunometric assay for cortisol based on idiotype-anti-idiotype reactions. Analytica Chimica Acta, 638(1), 94-100.

Prasad, K.; Prathish, K. P.; Gladis, J. M.; Naidu, G. R. K.; \& Rao, T. P. (2007). Molecularly imprinted polymer (biomimetic) based potentiometric sensor for atrazine. Sens. Actuators B: Chem.., 123(1), 65-70.

Sheedy, C.; Mackenzie, C. R. \& Hall, J. C. (2007). Isolation and affinity maturation of haptenspecific antibodies. Biotechnology Advances, 25(4), 333-352.

Shirasu, N.; Onodera, T.; Nagatomo, K.; Shimohigashi, Y.; Toko, K. \& Matsumoto, K. (2009). Noncompetitive immunodetection of benzaldehyde by open sandwich ELISA. Analytical Sciences, 25(9), 1095-1100.

Spinks, C. A. (2000). Broad-specificity immunoassay of low molecular weight food contaminants: new paths to Utopia. Trends Food Sci. E Tech., 11(6), 210-217.

Suri, C. R.; Boro, R.; Nangia, Y.; Gandhi, S.; Sharma, P.; Wangoo, N.; Rajesh, K. \& Shekhawat, G.S. (2009). Immunoanalytical techniques for analyzing pesticides in the environment. Trends in Analytical Chemistry. 28(1), 29-39.

Suzuki, T.; Munakata, Y.; Morita, K.; Shinoda, T. \& Ueda, H. (2007). Sensitive detection of estrogenic mycotoxin zearalenone by open sandwich immunoassay. Analytical Sciences, 23(1), 65-70.

Tong, D. W.; Yang, H. S \& Wang J. Y. (2007). Recent advances in the synthesis of artificial antigen and its application in the detection of pesticide residue. American Journal of Agricultural and Biological Sciences, 2(2), 88-93.

Vlatakis, G.,; Andersson, L. I.; Muller, R. \& Mosbach, K. (1993). Drug assay using antibody mimics made by molecular imprinting. Nature, 361(2), 645-647.

Vandevelde, F.; Leichle, T.; Ayela, C.; Bergaud, C.; Nicu, L. \& Haupt, K. (2007). Direct patterning of molecularly imprinted microdot arrays for sensors and biochips. Langmuir, 23(12), 6490-6493.

Wang, C. M.; Li, X. B.; Liu, Y. H.; Guo, Y. R.; Xie, R.; Gui, W. J. \& Zhu, G. N. (2010). Development of a Mab-based heterologous immunoassay for the broad-selective determination of organophosphorus pesticides. J. Agric. Food Chem., 58(9), 56585663.

Wang, S. T.; Gui, W. J.; Guo, Y. R. \& Zhu, G. N. (2007). Preparation of a multi-hapten and broad specificity polyclonal antibodies for a multiple pesticide immunoassay. Analytica Chimica Acta, 587(2), 287-292.

Wang, S.; Allan, R. D.; Skerritt, J. H. \& Kennedy, I. R. (1998). Development of a class-specific competitive ELISA for the benzoylphenylurea insecticides. J. Agric. Food Chem., 46(8), 3330-3338. 
Ward, C. M.; Wilkinson, A. F.; Lee, H. A.; \& Morgan, M. R. A. (1999). Monoclonal antiidiotype antibody mimicking the pesticide binding site of cutinase: potential for broad specificity organophosphate recognition. J. Immunol. Meths., 224(1-2), 197202.

Watanabe, E.; Baba, K.; Eun, H. \& Miyake, S. (2007 a). Application of a commercial immunoassay to the direct determination of insecticide imidacloprid in fruit juices. Food Chem., 102(3), 745-750.

Watanabe, E. \& Miyake, S. (2007 b). Immunoassay for iprodione : Key estimation for residue analysis and method validation with chromatographic technique. Analytica Chimica Acta, 583(2), 370-376.

Watanabe, T.; Shan, G.; Stoutamire, D. W.; Gee, S. J. \& Hammock, B. D. (2001). Development of a class selective immunoassay for the type I pyrethroid insecticides. Analytica Chimica Acta, 444(1), 119-129.

Xu, Z. L.; Xie, G. M.; Li, Y. X.; Wang B. F.; Beier, R. C.; Lei, H. T.; Wang, H. Shen, Y. D. \& Sun, Y. M. (2009 a). Production and characterization of a broad-specificity polyclonal antibody for O,O-diethyl organophosphorus pesticides and a quantitative structure-activity relationship study of antibody recognition. Analytica Chimica Acta, 647(1), 90-96.

Xu, Z. L.; Shen, Y. D.; Beier, R. C.; Yang, J. Y.; Lei, H. T.; Wang, H. \& Sun, Y. M. (2009 b). Application of computer-assisted molecular modeling for immunoassay of low molecular weight food contaminants: A review. Analytica Chimica Acta, 647(2), 125136.

Zhang, Q.; Zhang, W.; Wang X. P. \& Li, P. W. (2010). Immunoassay development for the class-specific assay for type I and II pyrethroid insecticides in water samples. 15(1), 164-177. 


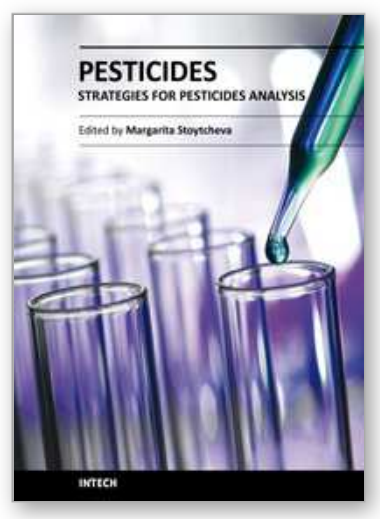

\author{
Pesticides - Strategies for Pesticides Analysis \\ Edited by Prof. Margarita Stoytcheva
}

ISBN 978-953-307-460-3

Hard cover, 404 pages

Publisher InTech

Published online 21, January, 2011

Published in print edition January, 2011

This book provides recent information on various analytical procedures and techniques, representing strategies for reliability, specificity, selectivity and sensitivity improvements in pesticides analysis. The volume covers three main topics: current trends in sample preparation, selective and sensitive chromatographic detection and determination of pesticide residues in food and environmental samples, and the application of biological (immunoassays-and biosensors-based) methods in pesticides analysis as an alternative to the chromatographic methods for "in situ" and "on line" pesticides quantification. Intended as electronic edition, providing immediate "open access" to its content, the book is easy to follow and will be of interest to professionals involved in pesticides analysis.

\title{
How to reference
}

In order to correctly reference this scholarly work, feel free to copy and paste the following:

Mingtao Fan and Jiang He (2011). Pesticides Immunoassay, Pesticides - Strategies for Pesticides Analysis, Prof. Margarita Stoytcheva (Ed.), ISBN: 978-953-307-460-3, InTech, Available from: http://www.intechopen.com/books/pesticides-strategies-for-pesticides-analysis/pesticides-immunoassay

\section{INTECH}

open science | open minds

\section{InTech Europe}

University Campus STeP Ri Slavka Krautzeka 83/A 51000 Rijeka, Croatia Phone: +385 (51) 770447 Fax: +385 (51) 686166 www.intechopen.com

\section{InTech China}

Unit 405, Office Block, Hotel Equatorial Shanghai No.65, Yan An Road (West), Shanghai, 200040, China 中国上海市延安西路65号上海国际贵都大饭店办公楼405单元 Phone: +86-21-62489820

Fax: $+86-21-62489821$ 
(C) 2011 The Author(s). Licensee IntechOpen. This chapter is distributed under the terms of the Creative Commons Attribution-NonCommercialShareAlike-3.0 License, which permits use, distribution and reproduction for non-commercial purposes, provided the original is properly cited and derivative works building on this content are distributed under the same license. 